Article

\title{
Engaging and Supporting a University Press Scholarly Community
}

\author{
Megan Taylor ${ }^{1, *(D)}$ and Kathrine S. H. Jensen 2 \\ 1 University of Huddersfield Press, Huddersfield HD1 3DH, UK \\ 2 Independent Research Consultant, Huddersfield HD1 3DH, UK, kathrineshjensen@gmail.com \\ * Correspondence: m.taylor2@hud.ac.uk
}

Received: 17 January 2018; Accepted: 22 March 2018; Published: 27 March 2018

\begin{abstract}
In this paper we explore how the development of The University of Huddersfield Press, a publisher of open access scholarly journals and monographs, has enabled the sharing of research with a wider online audience. We situate the development of the Press within a wider research environment and growing community of New University Presses (NUPs) where there is an increasing demand for demonstrating research impact, which drives the need for improved analysis and reporting of impact data, a task that often falls within the remit of library and academic support services. We detail the benefits of the University Press Manager role in terms of ensuring professional service that delivers consistency and sustainability. We go on to outline the experiences of engaging with different online spaces and detail the extensive support for student authors. We argue that in order for the Press to support building a strong and engaged scholarly community and provide new spaces for emerging research, continued investment in both platform development and infrastructure is required.
\end{abstract}

Keywords: open access; publishing; library; journals; monographs; scholarly communications; social media

\section{Introduction}

New University Presses (NUPs) are on the rise, with at least 17 now in existence just in the UK [1]. The majority of these are publishing open access research via journals and monographs [2], including the University of Huddersfield Press (the Press). Established in 2007, the Press has grown to become a primarily open access publisher of high quality research. Our authors and editorial boards bring international research expertise and a strong orientation to practice and real-world application to their publications. The Press is keen to support emerging researchers and foster research communities by providing a platform for developing or niche academic areas. The Press activities are aligned with the key tenets and identified strategic priorities of the University of Huddersfield Research Strategy [3] and all publications undergo a rigorous review process by our Press Editorial Board, in addition to individual journal editorial boards. We publish scholarly journals and monographs across a broad range of subject areas including Music, History, Art, Theatre, Pharmacy, Education, Politics and Literature, and our portfolio currently includes a pioneering student research journal, Fields: Journal of Huddersfield Student Research (Fields) [4]. The Press operates a not for profit business model, whereby any potential profits that could be made from monograph sales would be reinvested into the Press to fund the publication of further research.

As an open access publisher, a key function of the Press is to provide support to the scholarly community to aid dissemination of research and to promote the knowledge and skills needed for researchers to successfully engage with open access publishing. Through continually assessing and developing our approach to the publishing process and surrounding community support, we have 
found that a two-fold approach, encompassing systems development and resource infrastructure, is needed in order to create, support and curate these community spaces. This paper looks at how investing in systems and infrastructure together can help to build a strong and engaged scholarly community. For the scope of this paper, we have focused on five key areas of activity within the outlined approach:

- Developing resources for our community

- Publication workflow

- Support infrastructure

- Online community spaces

- Supporting student authors

\section{Developing Resources for Our Community}

Whilst the Press is meeting its aims and objectives of providing a platform for research and a support service for authors, the journey is not without its challenges, past and present. Limited resources and an organic growth rate, which can fluctuate unpredictably [5], has made consistency of procedures, documentation and services difficult to maintain. After internal research carried out with a selection of editors and authors, the Press has developed an online resource centre for authors and editors to help improve our levels of support and streamline the work involved in the production process. A space was created on the Press website to house a range of newly developed documents, including the House Style Guide, author license to publish, editor agreement and article template.

One of the main pieces of documentation to come out of this project was the House Style Guide [6]. A scoping project was carried out looking at existing style guides including those from Manchester University Press, University College London (UCL), and Liverpool University Press. From this project key areas were identified which were believed to be of importance to authors and editors, including fomatting, reference styles and copyright guidelines. Once an initial draft was ready it was shared with our journal editors and previous monograph editors and authors for their feedback and suggestions. Community input at this stage was integral to developing a guide which would be able to address the needs of those using it. Following the implementation of this guide we have already seen a reduction in the number of style queries and the level of alterations needed at the production stage.

In addition to the style guide the resource centre also houses article templates, proposal forms, editor contracts and licensing agreements for journal and monograph authors. The legal documents (licensing agreements and editor contracts) have been checked and approved by the University solicitor to ensure that all terms are appropriate and legally sound, giving a reassuring level of protection for authors and editors, and the Press.

Anecdotal feedback from current authors and editors has been overwhelmingly positive, with emphasis on the ease of access of these documents, and the practicality of having them all in one place to download whenever they need them. Having the documents in this online resource centre also ensures that authors and editors are always issued with the most up to date version.

\section{Publication Workflow}

The organic development of the Press has meant that, whilst the publishing and production workflow systems the Press had in place at the beginning were fit for purpose at the time, they have struggled to keep up with the relatively rapid pace of expansion in recent years. We now have 10 active journals and publish around two monographs a year. With a staff total of 0.6, which is below the NUP average of 1 FTE [1], it is important to have systems in place that enable a professional, efficient and effective publishing process that suits our journal and monograph portfolio.

Developments across the wider research environment, including OA requirements of research assessment exercises and an increasing emphasis on impact, alongside the above mentioned internal resource pressures, have directed the need for change. With academic staff under increasing pressure 
to demonstrate research impact, not just in terms of scholarly impact but also impact on communities and end users, the need for improved analysis and reporting is continually growing. This increase in demand for demonstration of research impact and environment highlights the importance of properly funded and resourced support within the Library to deliver this across universities and ensure academic staff are well prepared and supported in these needs.

Pre-empting the requirement for this kind of data ahead of the Research Excellence Framework in 2021 [7] has led the Press to carry out a large scoping project looking at the relevant publishing requirements and the range of platforms available that might be best suited to meet these needs. A full analysis of the publishing platform project is out of scope for this paper, but for information the basic requirements identified are listed below:

- Full journal publication platform from submission to publication

- Pre-production checklist

- Integrated copyediting stage

- COUNTER compliant

- Crossref compatible

- Linked with ORCID

- PDF proof production

- High level statistics analysis

- Administration dashboard

- Front end monograph section

- Chapter level metadata for monographs

At the time of writing the Press has identified a platform to address these requirements and details will follow in a second paper later this year.

\section{Support Infrastructure}

The Press was launched in 2007 as a result of the personal interest in open access of the Repository Manager at the time. Slowly the Press grew in both reputation and number of publications, but it was still being managed as a side project to the Repository Manager's main role responsibilities. The Press Manager role was established by the Library in 2016 in a move to recognise and meet the need for a higher level of dedicated professional resource for the Press. The aim was to create a separate post to the Repository Manager, one which could focus solely on the Press and improve levels of service in addition to expanding operations. This post is funded by the Library budget as a permanent post, and there is a small budget also funded by the Library to spend on book production, marketing and platforms. Currently a 0.6 FTE, the Press Manager has an internal and an external focus in terms of raising the awareness of and developing the Press' portfolio. Acting as first point of contact for researchers who are interested in starting a new journal, transferring an existing journal or publishing a monograph, the Press Manager also has responsibility for active commissioning, raising awareness of open access publishing and developing and evaluating publishing processes, platforms and resources. A large part of this role is managing community relationships with authors, editors, reviewers and researchers.

By investing in this role, the Library and the University are recognising the need for support infrastructure in library publishing and the importance of supporting a professional and informed approach to open access publishing. The role has been strategically created within the Information Resources Team, as part of Academic Services in Computing and Library Services. As a result of this role the Press has been able to establish a wide range of best practice activities that are enhancing the publishing experience for our scholarly community, including:

- Annual review meetings for each journal

- A move to an improved publishing platform 
- Tailored marketing plans for each title

- Streamlined sales and distribution processes for monographs

- Social media management and analysis

- A standardised publishing production workflow

- Legal documentation to ensure the rights of authors and editors

\section{Online Community Spaces}

Through a range of platforms and channels including the Press website, Twitter, Facebook and WordPress sites, opportunities have been created for authors to come together and form a community to support each other, find information they need, and raise awareness of publications. Much of this work has been focused on four key platforms: Twitter, Facebook, WordPress and Jiscmail.

Twitter was the first platform to be utilised as it was identified as a popular social media channel for researchers across a wide range of subject areas. The Press Twitter account is used to raise awareness at Press and publication level via a structured marketing plan [6] which ties in the wider scholarly community by linking to relevant author and organisation accounts. This platform also allows the Press to get involved in national and international scholarly events such as Open Access Week and Peer Review Week, creating opportunities to share resources with our community in these key areas.

Facebook has proved less immediately popular than twitter for the Press, but nevertheless our community is growing steadily and the platform has some particular features that we would otherwise miss out on. In particular, it allows the Press to link closely with the social media marketing campaigns directed at our student research community, by linking posts to our Students Union, Student Alumni and School-specific groups. This proves especially useful in the case of our student research journal Fields, for helping to raise awareness across a diverse range of student groups.

The WordPress blog [8] functions as a content hub that other social media platforms can signpost back to. The blog features interviews with authors, excerpts from publications, reviews of relevant events, and posts written by editors. This platform has proved ideal for creating a space where researchers can tell our readers more about their research in an informal discussion style, whilst always linking back to the original underpinning publication to help drive downloads and, ultimately, citations. The Press has followed the model demonstrated by Professor of Digital Humanities at University College London, Melissa Terras [9], in terms of providing enhanced content based around a publication to increase readership and make the work more accessible to a wider audience. In 2017 the Press blog received over 1500 views from across a wide range of countries with the majority of views coming from the UK, US, India and Germany (see Figure 1). The in-built analytics show that the majority of traffic coming to the blog is from social media platforms (see Figure 2), and this has been reflected in the analytics from the Press Facebook and Twitter accounts, which show posts highlighting the blog are highly shared and retweeted.

The new platform mentioned in the previous publication workflow section will provide us with further opportunities to analyse how our activity across the above online platforms is translating into downloads and citations. At the time of writing the Press has seen a recent rise in citations to some journals, with Fields in particular attracting an impressive three citations to its first ever issue [10]. Future research using improved analytics will enable the Press to look at links between the different communication and dissemination activities and the peaks and troughs in citation levels.

In addition to working to create and curate spaces for author communities to come together, the Press also works with other presses to share best practice in an effort to continually improve our resources and support for authors. Following discussions between the Press and colleagues working across the library and publishing sector, it was found that many NUPs were undergoing similar processes and facing similar challenges, and yet don't always find it easy to share resources or access advice. The Press set up the University Press and Publishing Jiscmail list [11] to provide a space for collaboration and best practice sharing, and to foster a sense of community around university presses. In the 18 months since it has been set up there have been over 60 separate discussions involving 
over 100 subscribers on subjects ranging from publishing platform companies to ways to manage information and ideas for event management.

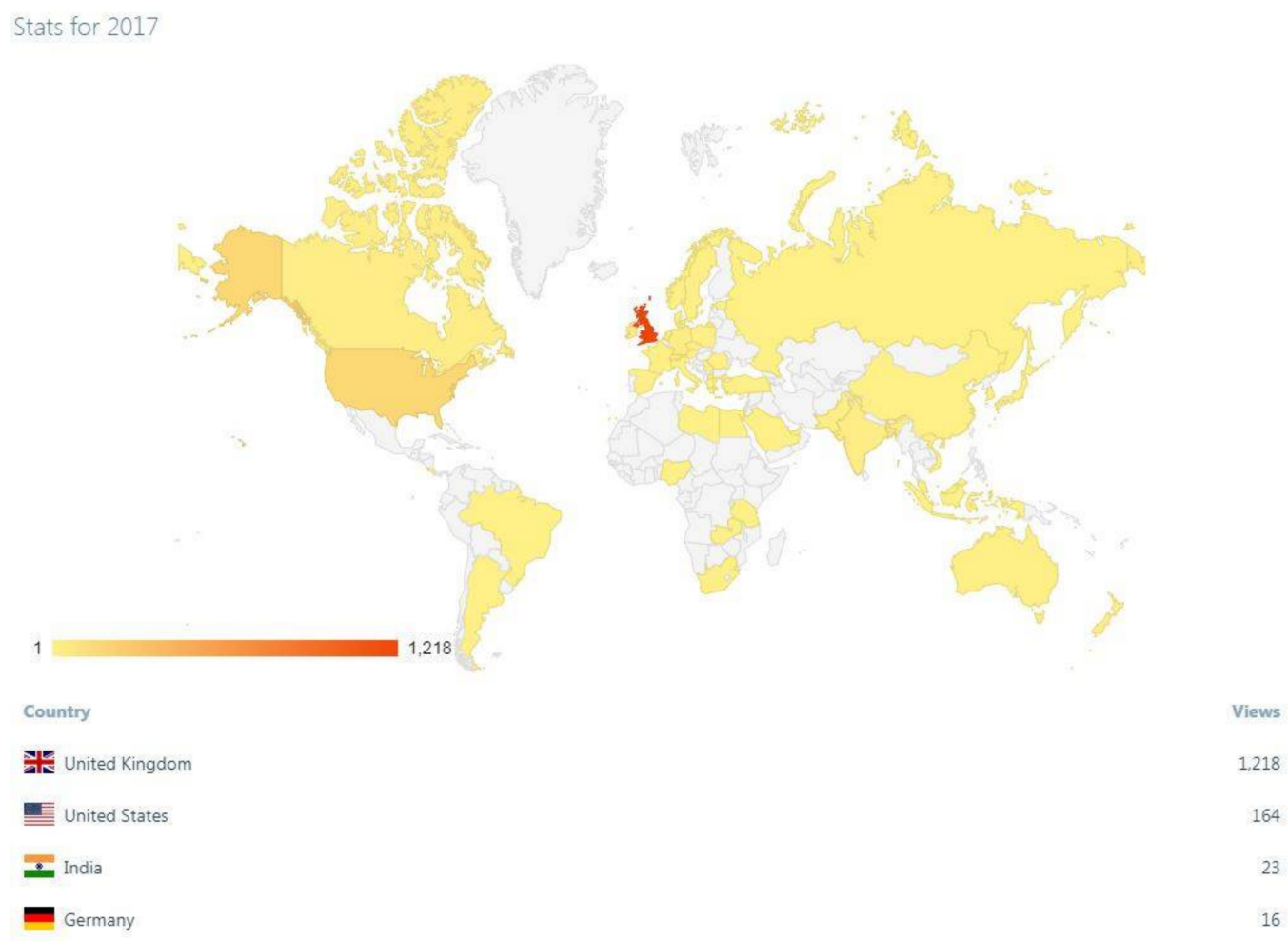

Figure 1. Blog views by geographical location 2017.

\section{Stats for 2017}
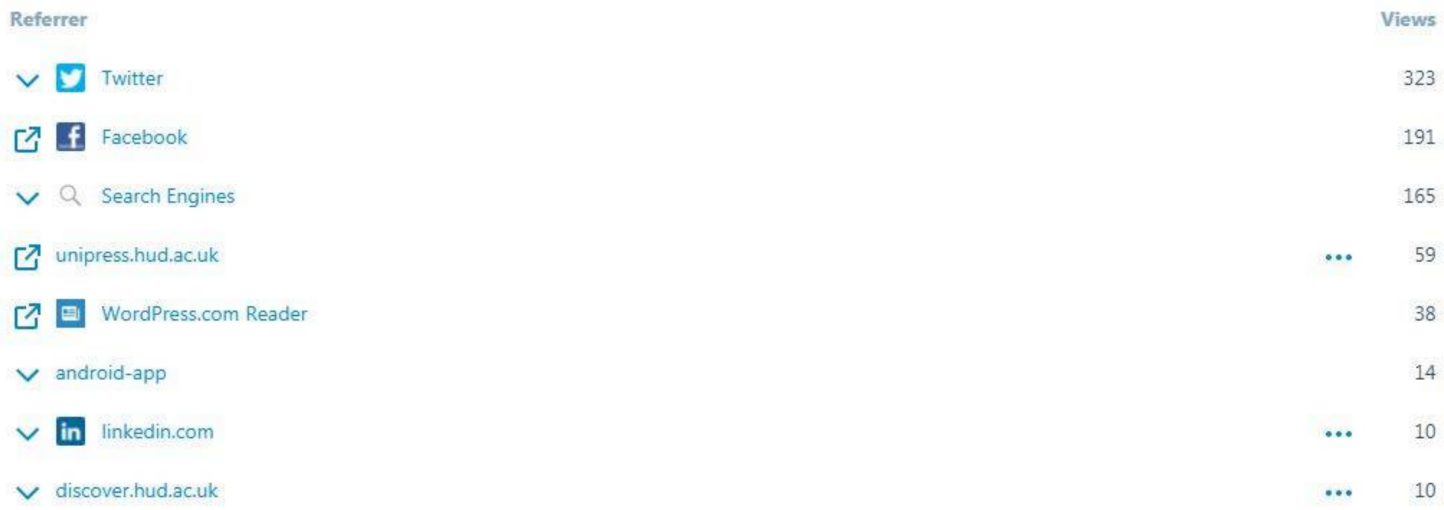

Figure 2. Blog referrers for 2017.

\section{Supporting Student Authors}

In addition to developing author support across the journal and monograph portfolio, the Press also carries out activities specifically designed for student author support as part of our journal of undergraduate research, Fields. Most of the students published in Fields did not have any previous experience of the academic publishing process so we developed a number of resources and activities in order to support them. This support ranged from bursaries to ensure students could afford the time to edit and rewrite their work, a writing retreat, written resources explaining the process of copy 
editing and writing an abstract to drop in sessions. After each volume of Fields, students were asked to give feedback on their experience and evaluate the activities on offer and we used this to enhance the activities and edit the journal guidance. In addition, all of the students were also encouraged to submit a poster or a presentation to the British Conference for Undergraduate Research [12] and if they did attend they wrote up their experiences as a blog post for the Teaching and Learning Institute (TALI) blog. Whilst Fields was launched out of a project run by TALI, the Institute has since closed and future issue of Fields are being organised solely by the Press. As a result of this, future reflections from student authors will be published via the Press blog, and promoted over the Press social media channels.

\subsection{Publishing as Skills Development}

Fields was set up not only as a way to make excellent undergraduate research available but also as to give students an opportunity to develop and hone their writing for publication skills. Activities at the writing retreat focused on what makes a good abstract, how to choose keywords, writing jargon free and more. Additional drop in sessions were set up to offer a second support point and to include the students who were unable to attend the writing retreat so they could raise any queries about the journal requirements.

The main aim of the writing retreat was to get the students familiar with the journal requirements and get them started on writing in an environment where they could ask questions as facilitators were present throughout the day. At the writing retreat the students also had the opportunity to share their research and paper ideas with other students and student feedback indicated that talking to and getting to know student work from other disciplines was really appreciated. In fact, feedback from the 2016 writing retreat included a request for the students to be enabled to form a support community by finding a way to actively share their contact details. This is something that the Press is planning to include in the publication workflow for our next Fields issue.

Another feature of the writing retreat is the Editorial Panel. This aspect was included to give the students the opportunity to ask questions about the publishing process from experienced academics. The colleagues on the editorial panel was briefed to talk about typical issues that first time authors might encounter and to offer their editorial perspective so that the students could get a better understanding of the full publishing process.

It is clear from the student feedback collected as part of the evaluation process, and analysed in a previous article published on Fields [4], that Fields has been very successful in developing academic writing skills. Students had to consider their audience, explain subject jargon and take on board critical feedback from their supervisors, the editorial board as well as the copy editor.

My journal was based on my final year project report which was a considerably larger body of work; this experience therefore provided experience in extracting key information and creating a more concise article. It also meant I was able to identify what information from my report would be suited to an academic style paper, adapting certain sections to explain terminology and provide context. Writing for a wider audience, with the aim to interest and educate the reader, was a challenge I enjoyed throughout the process.

Nick Horne, engineering student

I feel my ongoing studies have vastly improved due to the new level of scrutiny I can impose on my own writing and content after working with the Fields team so closely to re-draft and improve my work throughout the past year. Attention to detail was never a strength of mine, but this experience demanded a high level of this skill and so I can now apply this both academically and professionally to my other projects.

Katie McAdam, history student

All of the students were proud to be published. For at least one student being published increased their confidence in their own abilities and made a really positive difference to their professional lives. 
Having my research published in Fields has been the pinnacle of my achievements, particularly as I am working full-time with a young family. It has enabled me to finally believe in my own abilities as a writer and researcher, as well as raising my professional status in my workplace.

Student author

Lessons so far from having students attend a writing retreat have included the importance of icebreaker activities, activities that actively allow the students to apply new knowledge about the journal requirements, space for students to work independently as well as in groups and keeping the environment as informal as possible. It can sometimes be difficult to achieve an informal feel if the event takes place on campus. It is also important to realise that not all students are comfortable writing in a space with other people and this needs to be taken into account.

\subsection{Open Access: Making Student Research Available}

At the writing retreat we made it clear to the students that the journal was open access and that this meant the content was freely available online and this was further emphasised by the copyright permission that all students signed. It is difficult to say to what extent the explanation of open access meant at this point as students were more concerned with the writing itself. However, a growing understanding of open access in our student authors can be seen in part of a series of Author Spotlight blog posts on the University Press blog [13]:

Open access not only allows fellow researchers, potential collaborators or interested and curious individuals from anywhere in the world to gain free access to essential information and insight but it also provides the researcher with a breadth of demonstrable tools, experiences and skills when seeking further employment, applying for funding or when building a portfolio of work. Allowing free access to research may actually be essential as the arts typically suffer from funding cuts, with some secondary schools recently appearing in the mainstream news for removing music and arts education from their curriculum altogether. Open access publishing not only provides students and researchers with viable methods to disseminate their work but it also expands the opportunity for anyone, anywhere, to gain access to essential inspirational and educational material.

\section{Conclusions}

The University of Huddersfield Press is part of a growing collection of NUPs within the UK library and publishing sector. There are increasing demands from the wider research environment for scholarly research to be available and accessible to public, private and professional audiences as well as the traditional academic sector $[14,15]$. Huddersfield, like many other NUPs, focuses on addressing the requirements of the research environment by providing an open access platform that is enriched by a high level of scholarly community activity and support. It is important to recognise that high quality community support requires both investment in systems/platforms, as well as investment in infrastructure. This paper has explored five of the key areas the Press recommends focusing on when providing support for authors: developing resources, publication workflow, support infrastructure, online community spaces and supporting student authors. Further research remains to be done in terms of the processes of implementing a new publication workflow system, and looking at ways in which analytics can help to identify relationships between online communication activities and article and monograph downloads.

Author Contributions: Both authors worked on this research and carried out the analysis and discussion jointly. Conflicts of Interest: The authors declare no conflict of interest. 


\section{References}

1. Adema, J.; Stone, G. Changing Publishing Ecologies: A Landscape Study of New University Presses and Academic-Led Publishing; Jisc: London, UK, 2017.

2. Lockett, A.; Speicher, L. New university presses in the UK: Accessing a mission. Learn. Publ. 2016, 29, 320-329. [CrossRef]

3. University of Huddersfield. Research Strategy and Governance. 2018. Available online: https://research. hud.ac.uk/strategy / (accessed on 17 January 2018).

4. Stone, G.; Jensen, K.; Beech, M. Publishing undergraduate research: Linking teaching and research through a dedicated peer-reviewed open access journal. J. Sch. Publ. 2016, 47, 147-170. [CrossRef]

5. Stone, G. Developing a Sustainable Publishing Model for a University Press: A Case Study of the University of Huddersfield, 2011-2015. Ph.D. Thesis, University of Huddersfield, Huddersfield, UK, 2017.

6. Taylor, M. Forms for Authors; University of Huddersfield: Huddersfield, UK, 2017.

7. HEFCE. The Second Research Excellence Framework. 2017. Available online: http://www.hefce.ac.uk/ rsrch/ref2021/ (accessed on 17 January 2018).

8. Taylor, M. About University of Huddersfield Press. 2017. Available online: https://hudunipress.wordpress. com/about/ (accessed on 17 January 2018).

9. Terras, M. Melissa Terras' Blog. 2012. Available online: http://melissaterras.blogspot.co.uk/2012/04/isblogging-and-tweeting-about-research.html (accessed on 17 January 2018).

10. Jensen, K.; Research by Huddersfield Students is Accessible and Citeable. Teaching and Learning Institute. 2017. Available online: https:/ / theinstituteblog.co.uk/2017/05/24/research-by-huddersfield-students-isaccessible-and-citeable/ (accessed on 17 January 2018).

11. Jisc. JiscMail-Universitypress Home Page. 2017. Available online: https://www.jiscmail.ac.uk/cgi-bin/ webadmin?A0=UNIVERSITYPRESS (accessed on 17 January 2018).

12. BCUR. British Conference of Undergraduate Research. Available online: http:/ /www.bcur.org/ (accessed on 17 January 2018).

13. Fox, J.; Author Spotlight: Open Access Publishing and Video Art. University of Huddersfield Press. 2017. Available online: https:/ / hudunipress.wordpress.com/2017/03/23/author-spotlight-open-accesspublishing-and-video-art/ (accessed on 17 January 2018).

14. Mudditt, A. The past, present, and future of American university presses: A view from the left coast. Learn. Publ. 2016, 29, 330-334. [CrossRef]

15. Mrva-Montoya, A. Open Access Strategy for a 'New' University Press: A View through the Stakeholder Lens. J. Sch. Publ. 2017, 48, 221-242. [CrossRef]

(C) 2018 by the authors. Licensee MDPI, Basel, Switzerland. This article is an open access article distributed under the terms and conditions of the Creative Commons Attribution (CC BY) license (http://creativecommons.org/licenses/by/4.0/). 